\title{
Identification and molecular modelling of a novel familial mutation in the $S R Y$ gene implicated in the pure gonadal dysgenesis
}

\author{
Giorgio Gimelli ${ }^{*}, 1$, Stefania Gimelli ${ }^{2}$, Nazzareno Dimasi ${ }^{3}$, Renata Bocciardi ${ }^{4}$, \\ Eliana Di Battista ${ }^{5}$, Tiziano Pramparo ${ }^{2}$ and Orsetta Zuffardi $^{2}$
}

\begin{abstract}
${ }^{1}$ Laboratorio di Citogenetica, Istituto G Gaslini, Genova, Italy; ${ }^{2}$ Biologia Generale e Genetica Medica, Università di Pavia, Pavia, Italy; ${ }^{3}$ Laboratorio di Medicina Molecolare, Istituto G Gaslini, Genova, Italy; ${ }^{4}$ Laboratorio di Genetica Molecolare, Istituto G Gaslini, Genova, Italy; ${ }^{5}$ DIPE, Università di Genova, Istituto G Gaslini, Genova, Italy
\end{abstract}

$S R Y$ gene is responsible for initiating male sexual differentiation. The protein encoded by $S R Y$ contains a homeobox (HMG) domain, which is a DNA-binding domain. Mutations of the SRY gene are reported to be associated with $X Y$ pure gonadal dysgenesis. The majority of these are de novo mutations affecting only one individual in a family. Only a small subset of mutations is shared between the father and one or more of his children. Most of these familial mutations are localized within the HMG box and only two are at the $\mathrm{N}$-terminal domain of the SRY protein. Herein, we describe a young girl with pure gonadal dysgenesis and her father carrying a novel familial mutation in the $S R Y$ gene at codon number 3 . This mutation is resulting in a serine $(S)$ to leucine $(L)$ substitution. The secondary structure of the SRY protein was carried out by protein modelling studies. This analysis suggests, with high possibility, that the N-terminal domain of the SRY protein, where we found the mutation, could form an $\alpha$-helix from amino acid in position 2 to amino acid in position 13 . The secondary structure prediction and the chemical properties of serine to leucine substitution stands for a potential disruption of this $\mathrm{N}$-terminal $\alpha$-helix in the SRY protein. This mutation could have some role in impeding the normal function of the SRY protein.

European Journal of Human Genetics (2007) 15, 76-80. doi:10.1038/sj.ejhg.5201719; published online 25 October 2006

Keywords: XY female; gonadal dysgenesis; SRY gene; familial mutation; protein modelling

\section{Introduction}

The SRY gene is located in the distal region of the short arm of the $\mathrm{Y}$ chromosome and is responsible for initiating male sexual differentiation. ${ }^{1,2}$ The protein encoded by $S R Y$ contains a homeobox (HMG) domain, which is a DNA-binding domain present in some chromatin-associated proteins of the high mobility group family, and in some transcription factors. SRY, as for the SOX proteins,

*Correspondence: Dr G Gimelli, Laboratorio di Citogenetica, Istituto G Gaslini, L.go G.Gaslini 5, I-16148 Genova, Italy.

Tel: + 39010 5636371; Fax: + 39010 382639;

E-mail: gimcyto@hotmail.com

Received 15 May 2006; revised 19 July 2006; accepted 15 August 2006; published online 25 October 2006 specifically binds the DNA through the HMG domain. This domain folds into an L-shaped structure composed of three helices that binds to DNA in the minor groove. However, protein sequences outside the HMG domain are variable for both structure and function.

These sequences are required to stabilize protein binding and/or generate specificity by helping to discriminate between protein partners. ${ }^{3}$ SRY is thought to work as an architectural factor modulating local chromatin structure in the vicinity of target genes to favour the assembly of the transcriptional machinery. ${ }^{4,5}$

In XY humans, mutations of $S R Y$ cause male-to-female sex reversal. Sex reversal in XY females results from the failure of the indifferent gonad to develop into a testis. 
At birth, the patients with this type of gonadal dysgenesis appear to be normal females; however, they do not develop secondary sexual characteristics at puberty, have amenorrhea and streak gonads. Phenotypic abnormalities in these patients could be diverse and heterogeneous depending on the precise moment of testicular degeneration and if both testicular compartments are totally or partially affected. Thus, the phenotype of an individual with an SRY mutation is either XY-female or normal fertile male. Intersex individuals do not have SRY mutations.

Mutations in the $S R Y$ gene have been found to account for approximately $15 \%$ of cases with male to female sex reversal. To date, about 46 mutations have been identified within the open reading frame of the $S R Y$ gene. ${ }^{6}$ Primarily, these mutations are within the HMG box, thus highlighting the critical role of this domain, and only 10 mutations outside the HMG box have been reported so far to the best of our knowledge. Of these, eight are located in the $5^{\prime}$ region upstream of the HMG box, and the remaining two lie downstream the HMG box. ${ }^{6,7}$ Although some $S R Y$ missense mutations affect DNA binding and bending activities, it is unclear how others mutations contribute to disease. The importance of the HMG box to $S R Y$ function is highlighted by the fact that most of patients with pure gonadal dysgenesis presented mutations of $S R Y$ clustered within this motif. ${ }^{8}$ The majority of the $S R Y$ variants are de novo mutations, affecting only one individual in a family. However, a small subset of these reports describes familial mutations, shared between the father and one or more of his children. ${ }^{9}$

Paternal mosaicism for the mutant $S R Y$ provided an explanation for the familial inheritance ${ }^{10}$ or was ruled out based on the transmission of the mutant allele to paternal relatives of the proposita. ${ }^{9}$ In one case, paternal mosaicism could not be investigated because the proposita's father was deceased at the time of the study. ${ }^{11}$ At last, in a new familial case a gonadal mosaicism cannot be completely excluded. ${ }^{9}$ At the best of our knowledge, only the familial mutations $\mathrm{Y} 17 \mathrm{X}^{11}$ and $\mathrm{S} 18 \mathrm{~N}^{12}$ were localized at the N-terminal domain of the SRY protein, whereas all the other familial mutations were localized within the HMG box.

Herein, we report a novel mutation in the $S R Y$ gene (S3L) identified in a young woman affected with gonadal dysgenesis. This woman has a male karyotype and shares the mutation with her father. We propose, based on protein molecular modelling, that this mutation could impair the normal function of the SRY protein.

\section{Subjects and methods Clinical investigations}

The proposita (LS), a 17.5-year-old girl, was referred to our Paediatrics Department for primary amenorrhea without history of previous illness. She is the first daughter born from nonconsanguineous healthy parents. Her mother's pregnancy and delivery were normal.

At the time she arrived at the hospital, her height was $169.4 \mathrm{~cm}$, the weight was $56.3 \mathrm{~kg}$ and the skeletal age was 13.5 years old based on Greulich-Pyle's bone age calculation. She presented female external genitalia with normal developed pubic and axillary's hair (Tanner stage 4), but absent breast development. Endocrine evaluation of pituitary gonadal axis showed elevated serum gonadotropin concentrations (LH $36.2 \mathrm{mU} / \mathrm{ml}$, FSH $122 \mathrm{mU} / \mathrm{ml}$ ), with undetectable gonadal steroids $(17-\beta$-estradiol $<20 \mathrm{pg} / \mathrm{ml}$, total testosterone $<20 \mathrm{ng} / \mathrm{dl}$ ). The adrenal steroids, prolactin and thyroid hormones, were in the normal range for her age. Imaging with ultrasound and magnetic resonance was performed in order to delineate the internal genital anatomy. These analyses showed a remnant uterus with a very short and narrow 'pseudo-vagina' and small rudimental gonads (streak gonads). After gonadectomy's surgery, which was performed in order to prevent the possible development of germinoma or gonadoblastoma, oestrogen replacement therapy was started. At last observation, when the proposita was 17.9 years old, the breast Tanner stage was 3 and the pelvic ultrasound showed a sufficient uterine response to the oestrogen replacement therapy with an initial pubertal differentiation shape and a subtle endometrial stripe.

\section{Cytogenetic and genetic analysis}

Chromosome analysis was performed on peripheral blood obtained from the proposita and her father after informed consent. Conventional GTG and QFQ banding was performed on blood lymphocytes. Karyotype analysis was performed, also, on fibroblasts derived from the skin and gonadal biopsies. A lymphocytes EBV-transformed cell line was prepared from the proposita and her father.

For mutational studies, genomic DNA was extracted from lymphoblast cultures by GenElute Blood Genomic DNA Kit (Sigma Aldrich), according to the manufacturer's instructions. DNA from the skin and gonadal tissue biopsies was prepared using the Puregene DNA purification kit (Gentra, Sys.). $S R Y$ amplification and sequencing were performed by PCR amplification using primers: $S R Y$ forward: $5^{\prime}$-gaatctggt agaagtgagttttgga- $3^{\prime}$ and $S R Y$ reverse: $5^{\prime}$-acgataacttacagccctc acttt- $3^{\prime}$. PCR reaction was performed in a $30 \mu \mathrm{l}$ volume containing $100 \mathrm{ng}$ DNA, $10 \mathrm{pmol}$ each forward and reverse primer, $200 \mu \mathrm{M}$ dATP, dTTP, dGTP and dCTP, $1 \times$ PCR buffer, $1.5 \mathrm{mM} \mathrm{MgCl}_{2}$ and $5 \mathrm{U} / \mu \mathrm{l}$ of Taq DNA Polymerase (Invitrogen). After an initial denaturation step at $96^{\circ} \mathrm{C}$ for $5 \mathrm{~min}, \mathrm{PCR}$ reaction was carried out at $95^{\circ} \mathrm{C}$ for $30 \mathrm{~s}, 60^{\circ} \mathrm{C}$ for $30 \mathrm{~s}$ and at $72^{\circ} \mathrm{C}$ for $30 \mathrm{~s}$ for 35 cycles, with a final extension step at $72^{\circ} \mathrm{C}$ for $7 \mathrm{~min}$ in a Thermalcycler PCR machine (Bio-Rad). ${ }^{13}$

Unincorporated dNTPs and primers were removed by using the Ultra Clean PCR Clean-Up Kit (Mo-Bio Laboratories, Inc.). DNA sequencing was performed with the PCR 
primers using the BigDye Terminator v3.1 Cycle Sequencing Kit and DNA sequences were run on a ABI PRISM ${ }^{\circledR}$ 3100 Genetic Analyzer (Applied Biosystems, Foster City, CA, USA). The chromatograms were analysed using the program Chromas 3.1.

\section{Protein homology modelling}

The SRY secondary structure prediction was carried out using the programs Polyview ${ }^{14}$ and DSSP. ${ }^{15}$ The HMG box three-dimensional structure from amino acid 60 to amino acid 128 was retrieved from the protein data bank (PDB) using the accession number 1HRZ. For the N-terminal domain (amino acid 1 to 59), no similar three-dimensional structure was found in the PDB. Therefore, the amino-acid sequence together with the secondary structure prediction was used in order to build a three-dimensional model. The three-dimensional model was build using the program Modeller. The figure was prepared using the program PyMol, Molscript and Render 3D.

\section{Results}

\section{Cytogenetics and molecular studies}

Chromosome analysis performed on blood, fibroblasts derived from a skin biopsy and from fibroblast-like cells cultured from both gonadal tissue. A normal male 46,XY karyotype was observed on 200 metaphases from lymphocyte's cultures, on 90 and 100 metaphases from the skin and gonadal biopsy, respectively.

The $S R Y$ gene was amplified and sequenced from blood, from both gonads and skin fibroblasts. In all these tissues, we have detected a novel point mutation in the SRY gene.

This mutation is at position 8 , in which a cytosine is replaced with a thymine at the third codon position. This change results in a serine to leucine substitution at aminoacid position 3 (S3L) of the entire SRY protein. The same mutation was detected on the blood from the healthy patient's father. We also performed as control, a $S R Y$ mutational study and no mutations were identified in 100 randomly selected males (data not shown). These data suggest that the mutation cytosine in position 8 to thymine $(8 \mathrm{C}>\mathrm{T})$ (Figure $1 \mathrm{a})$ is indeed a novel mutation and not a common human polymorphism.

\section{Protein modelling}

In order to understand, at molecular level, what this mutation could cause in the SRY protein, we have performed protein secondary structure prediction coupled with in silico molecular modelling. Presently, there is no three-dimensional structure for the entire SRY protein. Only the HMG domain, from amino acid 65 to 130 , complexed with the DNA is known. ${ }^{16}$ In order to build a three-dimensional model for the N-terminal domain of the SRY protein, where the mutation S3L is located, we performed a secondary structure prediction (Figure 1b).
Using this information, we were able to build a threedimensional model (Figure 1c). This analysis predicted, with a high possibility, that the N-terminal domain of the SRY protein could form an $\alpha$-helix from amino acid in position 2 to amino acid in position 13. The remaining part of this N-terminal domain is randomly coiled (Figure 1b, c). The mutation S3L takes place at the beginning of the $\alpha$-helix. This mutation could disrupt the N-terminal $\alpha$-helix.

\section{Discussion}

We have described a novel familial mutation in the $S R Y$ gene shared by an XY female with pure gonadal dysgenesis and her fertile and phenotypically normal father. This mutation takes place at nucleotide position 8 of the $S R Y$ single exon, where a cytosine in the codon third position is replaced with a thymine $(8 \mathrm{C}>\mathrm{T})$. At protein level, this mutation will change a serine with a leucine in amino-acid position 3 of the entire SRY protein (S3L). This S3L variant was demonstrated to be a mutation and not a common polymorphism by sequencing the $S R Y$ gene of 100 normal males (data not shown). Normal male sex determination, in mammals, is mediated by the $S R Y$ gene on the Y-chromosome and mutations in the $S R Y$ gene causes failure of testicular development that, in general, results in normal females with gonadal dysgenesis and complete male to female sex reversal.

The majority of the mutations detected in the SRY gene lie within the HMG box causing alterations in DNA binding/bending activity and therefore male to female sex reversal. Mutations that lie outside the HMG box have different effects on the phenotype of the patients. These regions might be required to stabilize the protein binding and to generate specificity by helping to discriminate between the protein-protein interactions. ${ }^{3,17}$

Although most of the mutations described in the SRY gene are de novo, some cases of fertile fathers and their $\mathrm{XY}$ daughters sharing the same altered $S R Y$ sequence have been reported. SRY is a transcription factor, like the other members of the SOX family of proteins. Timing and expression of this gene is exquisitely regulated and must probably reach the required threshold for testis formation in the developing embryo. ${ }^{18}$ Consequently, a given familial mutation in SRY against a particular genetic background may produce sufficient expression of the gene to reach the threshold required and testis formation ensues (eg, unaffected fathers). The same mutation in $S R Y$ on a different genetic background (eg, 46,XY daughters) may reduce $S R Y$ expression, such that it is unable to reach threshold, and thus prevents testis development. Whatever the mechanism, it appears that some $S R Y$ mutations are only conditionally sex reversing. ${ }^{19}$ However, a similar situation happens for SOX9 familial mutations where, the same mutation can or cannot induce sex reversal. ${ }^{20}$ We 

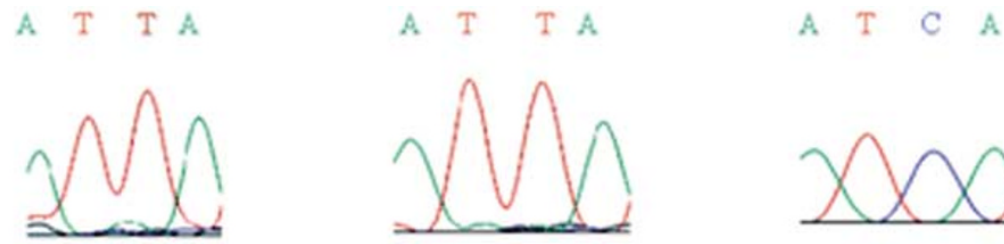

b

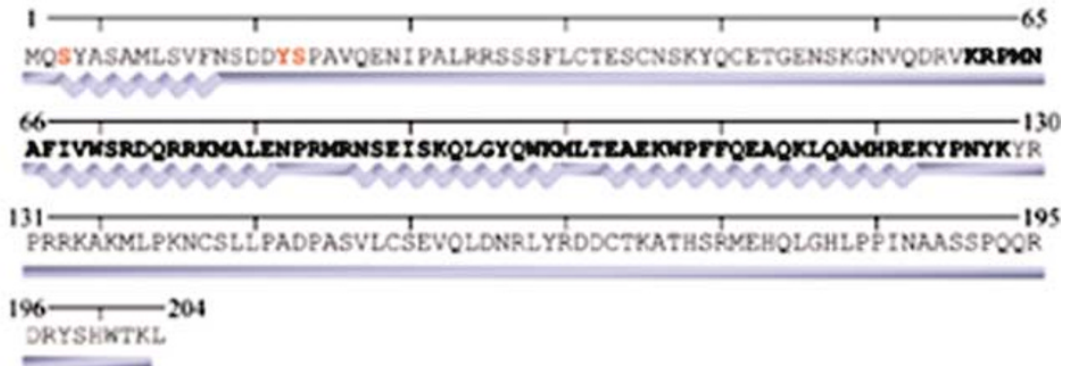

c

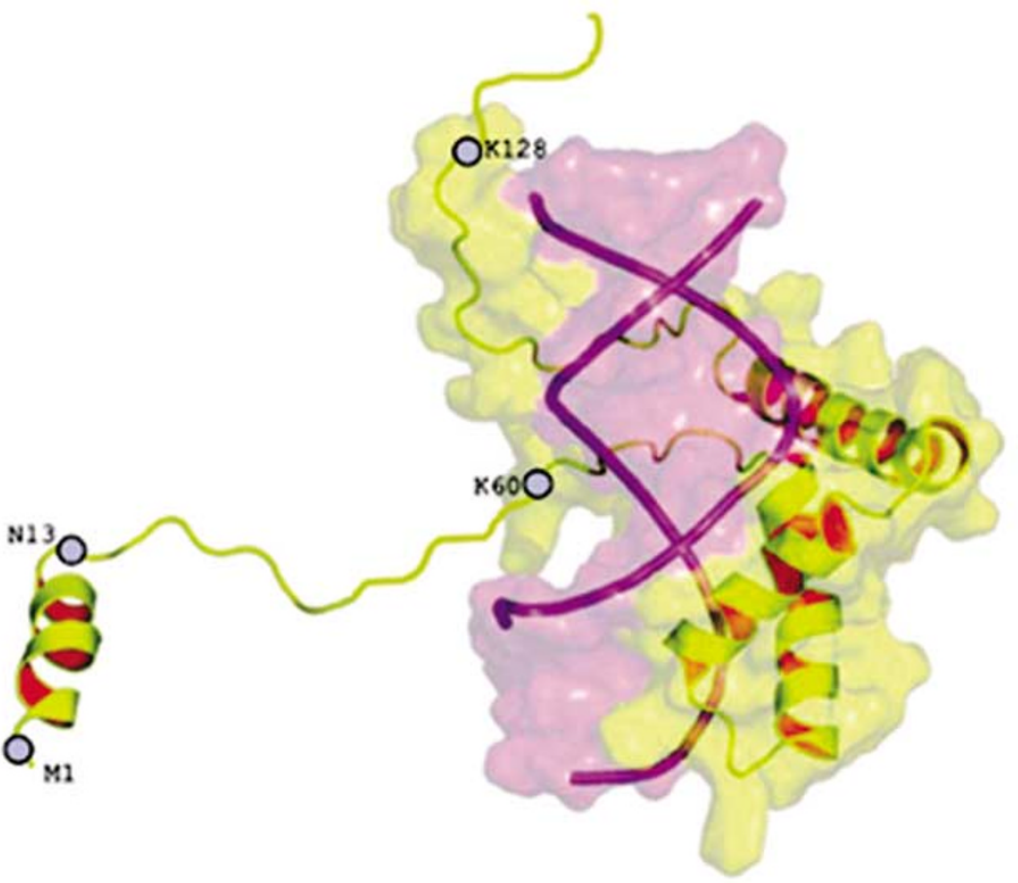

Figure 1 (a) Electropherogram of the 8ATT > ATC mutation found in the proposita and her father. Arrow shows the mutated nucleotide. (b) Amino acids sequence of the entire SRY protein. The mutated amino acids outside the HGM box are in red. The secondary structure prediction is in blue below the amino acids sequence, whereas the HMG box is represented in bold characters. (c) Model of the N-terminal domain and HMG structure of the human wild-type SRY protein. The human SRY gene codes for a protein of 204 residues that comprises three domains: an N-terminal domain from amino acid 1 to 59; a central DNA-binding domain, consisting of a single high mobility group (HMG) box, from amino acid 60 to 128 and a C-terminal domain from amino acid 129 to 204. The arrow indicates the predicted $\mathrm{N}$-terminal $\alpha$-helix shown as a ribbon together with the HMG domain complexed with the double-strand DNA. The surface is also shown for the DNA and the HMG.

could assume that it is possible that the S3L substitution is a polymorphism subtle enough to conserve the normal function of SRY and that the sex reversal of the proposita is caused by another mutation or an environmental influence during the development. However, we demon- strated that S3L variant is not a common polymorphism in 100 normal males.

Another possibility is that the proposita's father is an unusual mosaic harbouring lymphocytes and germ cells that carry the S3L mutation in SRY and other gonadal cells 
that carry wild-type $S R Y$. DNA studies of his lymphocytes suggest that there is no mosaicism in his peripheral blood cells (data not shown). However, because a gonadal tissue sample could not be obtained from the proposita's father, gonadal mosaicism cannot be completely excluded.

At protein level, it is likely that the mutation S3L could disrupt the formation of the potential N-terminal $\alpha$-helix. Interestingly, all the de novo mutations between the first and the 13th codon that compose the potential N-terminal $\alpha$-helix create a stop codon immediately following the initiating methionine and apparently inactivate the $S R Y$ gene destroying the protein function. ${ }^{21}$ Indeed, the serine is a relatively small, polar and hydrophilic amino acid, whereas the leucine is opposite: non-polar and hydrophobic. In addition, serine is generally solvent accessible and the leucine could be both solvent accessible or not. In general, serine could be substituted with alanine or threonine without perturbing the overall three-dimensional structure of a protein; but could not be substituted with a leucine without disrupting the three-dimensional structure. The serine could make side-chain hydrogen bonding, whereas the leucine could not. The former, could be relevant in protein-protein interaction. The secondary structure prediction and the chemical properties of serine and leucine stand for a potential disruption of the N-terminal $\alpha$-helix in the SRY protein. It is reasonable to assume that if this $\alpha$-helix is not present, then the SRY protein could be easily susceptible to proteolysis; could impede the binding of potential SRY partners, and lastly could play a major role in destabilizing the SRY interaction with the target DNA.

\section{Databases}

Protein Data Bank: http://www.rcsb.pdb; HGMD (2005): http://www.hgmd.cf.ac.uk/hgmd0.html/; Modeller: (http:// salilab.org/modeller/); PyMol: (http://pymol.sourceforge. net/); Molscript: (http://www.avatar.se/molscript/); Render 3D: (http://www.powerrender.com/).

\section{References}

1 Sinclair AH, Berta P, Palmer MS et al: A gene from the human sex-determining region encodes a protein with homology to a conserved DNA-binding motif. Nature 1990; 346: 240-244.

2 Koopman P, Gubbay J, Vivian N, Goodfellow P, Lovell-Badge R: Male development of chromosomally female mice transgenic for Sry. Nature 1991; 351: 117-121.

3 Wilson M, Koopman P: Matching SOX: partner proteins and co-factors of the SOX family of transcriptional regulators. Curr Opin Genet Dev 2002; 12: 441-446.
4 Wegner M: From head to toes: the multiple facets of Sox proteins. Nucleic Acids Res 1999; 27: 1409-1420.

5 Kamachi Y, Uchikawa M, Kondoh H: Pairing SOX off: with partners in the regulation of embryonic development. Trends Genet 2000; 16: 182-187.

6 Stenson PD, Ball EV, Mort M et al: Human Gene Mutation Database (HGMD): 2003 update. Hum Mutat 2003; 21: 577-581.

7 Shahid M, Dhillon VS, Aslam M, Husain SA: Three new novel point mutations localized within and downstream of high-mobility group-box region in SRY gene in three Indian females with Turner syndrome. J Clin Endocrinol Metab 2005; 90: $2429-2435$.

8 Knower KC, Kelly S, Harley VR: Turning on the male - SRY, SOX9 and sex determination in mammals. Cytogenet Genome Res 2003; 101: $185-198$.

9 Jordan BK, Jain M, Natarajan S, Frasier SD, Vilain E: Familial mutation in the testis-determining gene SRY shared by an XY female and her normal father. J Clin Endocrinol Metab 2002; 87: $3428-3432$.

10 Schmitt-Ney M, Thiele H, Kaltwasser P, Bardoni B, Cisternino M, Scherer G: Two novel SRY missense mutations reducing DNA binding identified in XY females and their mosaic fathers. Am J Hum Genet 1995; 56: 862-869.

11 Affara NA, Chalmers IJ, Ferguson-Smith MA: Analysis of the SRY gene in 22 sex-reversed $X Y$ females identifies four new point mutations in the conserved DNA binding domain. Hum Mol Genet 1993; 2: 785-789.

12 Domenice S, Yumie Nishi M, Correia Billerbeck AE et al: A novel missense mutation $(\mathrm{S} 18 \mathrm{~N})$ in the $5^{\prime}$ non-HMG box region of the SRY gene in a patient with partial gonadal dysgenesis and his normal male relatives. Hum Genet 1998; 102: 213-215.

13 Radi O, Parma P, Imbeaud S et al: XX sex reversal, palmoplantar keratoderma, and predisposition to squamous cell carcinoma: genetic analysis in one family. Am J Med Genet 2005; 138: 241-246.

14 Porollo AA, Adamczak R, Meller J: POLYVIEW: a flexible visualization tool for structural and functional annotations of proteins. Bioinformatics 2004; 20: 2460-2462.

15 Kabsch W, Sander C: Dictionary of protein secondary structure pattern recognition of hydrogen-bonded and geometrical features. Biopolymers 1983; 22: 2577-2637.

16 Werner MH, Huth JR, Gronenborn AM, Clore GM: Molecular basis of human $46 \mathrm{X}, \mathrm{Y}$ sex reversal revealed from the threedimensional solution structure of the human SRY-DNA complex. Cell 1995; 81: 705-714.

17 Shahid M, Dhillion VS, Jain N et al: Two new novel point mutations localized upstream and downstream of the HMG box region of the SRY gene in three Indian 46,XY females with sex reversal and gonadal tumour formation. Mol Hum Reprod 2004; 10: $521-526$

18 Cameron FJ, Sinclair AH: Mutations in SRY and SOX9: testisdetermining gene. Hum Mutat 1997; 9: 388-395.

19 Schafer AJ: Sex determination and its pathology in man. Adv Genet 1995; 33: 275-329.

20 Harley VR, Clarkson MJ, Argentaro A: The molecular action and regulation of the testis-determining factors, SRY (sex-determining region on the $\mathrm{Y}$ chromosome) and SOX9 [SRY-related highmobility group (HMG) box 9]. Endocr Rev 2003; 24: 466-487.

21 Brown S, Yu C, Lanzano P et al: A de novo mutation (Gln2Stop) at the $5^{\prime}$ end of the SRY gene leads to sex reversal with partial ovarian function. Am J Hum Genet 1998; 62: 189-192. 